\title{
FIN DEL EXPRESIONISMO NO-FIGURATIVO COSTARRICENSE CON OLA CRECIENTE (1967) DE RAFAEL ÁNGEL FELO GARCÍA PICADO (1928- )
}

\author{
End of the Costa Rican non-figurative expressionism Ola creciente (1967) \\ by Rafael Ángel Felo García Picado (1928- )
}

\author{
Daniel Montero Rodríguez ${ }^{*}$
}

\begin{abstract}
RESUMEN
El presente artículo consiste en un estudio del proceso de finalización de la pintura no-figurativo en la plástica costarricense, a través de la obra Ola creciente (1967) de Rafael Ángel Felo García, como un acercamiento a la pintura costarricense de la década de los setenta del siglo XX. Metodológicamente, se recurre al análisis semiótico del texto artístico, esto para interpretar el signo de manera gradual, a través de los tres niveles del signo (sintáctico, semántico y pragmático). Además, se conceptualizan las nociones de "expresionismo" y de "arte abstracto" como acercamiento teórico. Por otra parte, se refiere a la I Bienal Centroamericana de Pintura (1971) como contexto socio-histórico costarricense. Esto permite observar cómo el veredicto de dicho certamen tuvo influencia directa en el proceso de conclusión del arte nofigurativo costarricense, al tiempo que devela referencialidades no antes vistas, u obviadas por la crítica, en Ola creciente de este pintor costarricense.

Palabras clave: semiótica, expresionismo abstracto, no-figuración, pintura costarricense.
\end{abstract}

\begin{abstract}
This article presents a study about the end of the non-figurative painting in Costa Rica, taken Ola creciente (1967) by Rafael Ángel Felo García, as an approach to the Costa Rican painting of seventies in 20th century. The semiotic analysis of the artistic text is used as the method to interpret the sign gradually through three levels (syntactic, semantic and pragmatic). In addition, the notion of "expressionism" and "abstract art" is conceptualized as a theoretical approach. Conversely, the article refers to the 1 st Central American Biennial of Painting (1971) as a Costa Rican socio-historical context. This allows the reader not only to perceive how the outcome of this contest had a direct influence on the concluding process for the Costa Rican nonfigurative art, but also to unveil the references not seen before, or ignored by art critics, in the paint Ola creciente of this Costa Rican painter.
\end{abstract}

Key Words: semiotics, abstract expressionism, non-figuration, Costa Rican painting.

\section{Introducción}

La obra pictórica del artista costarricense Rafael Ángel Felo García es relevante no solo por la importancia de su aporte expresionista abstracto al medio plástico del país,

*Universidad de Costa Rica. Profesor de Artes Plásticas. Costa Rica.

Correo electrónico: danielmont84@gmail.com 
sino, a su vez, por la contribución de este artista a la producción y gestión cultural de Costa Rica. Lo anterior lo expresa la exdirectora ejecutiva de los Museos del Banco Central de Costa Rica, Dora María Sequeira, quien considera a García como un gestor cultural:

Gestor del Grupo 8, de la Escuela de Arquitectura de la Universidad de Costa Rica, del Colegio de Arquitectos, entre otros. Principalmente, fue gestor de la Dirección General de Artes y Letras y su primer director. Esta entidad, antecesora del actual Ministerio de Cultura, Juventud y Deportes, encontró con Felo el primer promotor cultural con un verdadero interés de llevar la cultura al pueblo. Bajo su dirección, las actividades culturales proliferaron llevando el teatro, la música y la danza a las comunidades por todo el territorio nacional (Alvarado-Venegas, Barquero-Segura y Quirós, 2005, p. 8).

Por su parte, es primordial analizar semióticamente la obra de García, pues se propone como la primera obra expresionista abstracta en el país. Como determina la estudiosa Eugenia Zavaleta Ochoa (1994): “En el caso de Felo García, éste se acogió, desde un primer momento, al expresionismo abstracto" (p. 38). Desde sus inicios, la propuesta del artista es una representación no-figuración; por lo tanto, para manejar un panorama completo de la pintura abstracta ${ }^{1}$ del país, es necesario investigar la propuesta de este artista, estableciendo así la perspectiva de la finalización de esta forma artística en Costa Rica.

\footnotetext{
${ }^{1}$ El concepto debe ser entendido en relación con la idea de arte abstracto, en este sentido, se asume como: "Abstracto, arte. Término cuyo sentido puede abarcar todo arte que no representa objetos reconocidos (buena parte del arte ornamental, por ejemplo), pero que se aplica más comúnmente a las formas del arte del siglo XX en que se abandona la concepción tradicional del arte europeo como imitación de la naturaleza" (Chilvers, 1995, p. 21). Es decir, no se concibe como pintura arreferencial, sino como un alejamiento de la imitación, por lo tanto, se interpreta como la pintura no tradicional en relación con el arte europeo.
} 
Al considerar estas producciones como representaciones del expresionismo abstracto $^{2}$ costarricense, es necesario cuestionarse cómo se da este fenómeno, sobre todo al reconocer que este movimiento artístico es de raíces europeizantes, y tuvo gran influencia en el medio cultural estadounidense. La obra del artista inició cuando este viaja a Inglaterra para completar sus estudios de arquitectura. Él mantenía la inquietud que había desarrollado por la pintura, al relacionarse con artistas como Manuel de la Cruz González y Teodorico Quico Quirós:

Ahora con más noción de su interés por la pintura, encontró que el panorama plástico londinense respondía a sus interrogantes con el expresionismo abstracto. La búsqueda concluyó al descubrir que los actores principales de la obra podían ser los elementos plásticos de la pintura -color, forma, línea, espacio, textura, movimiento- y no la realidad objetiva, consideración que en un medio como el costarricense hubiera sido difícil de estimar (Zavaleta-Ochoa, 1994, p. 9).

Indiscutiblemente, la obra pictórica londinense ejerció influencia sobre el trabajo de García, a través de elementos pictóricos que despertaron su interés al punto de volverse protagonistas en sus producciones.

Cuando el artista retornó a Costa Rica, volvió con nuevas perspectivas del quehacer artístico, estimulado por los enfoques de otros contextos culturales. Los artistas que viajaron al extranjero lograron cerrar periodos anteriores, que mantenían el arte pictórico nacional sumido en el academicismo, con lo cual implantó un novedoso

\footnotetext{
${ }^{2}$ Para comprender adecuadamente la acepción dentro de la abstracción, se requiere ahondar en la historia de este. En este sentido, el expresionismo abstracto se entiende como: "Término utilizado desde 1950 aproximadamente para denominar un movimiento artístico en el arte *abstracto que floreció en Nueva York en la década de 1940" (Chilvers, 1995, p. 335). Desde una perspectiva del movimiento artístico, este se distingue de otros estilos abstractos por el trabajo técnico, ya que da énfasis a la ejecución subjetiva de la pintura. El expresionismo se caracteriza por ser un "término utilizado en la historia y la crítica de arte para referirse al empleo de distorsiones y exageraciones con fines emocionales. Se utiliza en distintos sentidos y puede aplicarse a diversas manifestaciones artísticas, pero generalmente se relaciona con las artes visuales. En su sentido más amplio se aplica a cualquier forma de arte en la que predomina el sentido subjetivo por encima de la observación objetiva, reflejándose el estado anímico del artista más que las imágenes que conforma nuestra experiencia visual" (Chilvers, 1995, p. 334).
} 
panorama plástico. Para la estudiosa Ileana Alvarado Venegas rompen con un panorama aletargado:

Nuevas visiones irrumpen con energía el adormecido medio cultural. Lola Fernández, Felo García y Manuel de la Cruz González realizaron exposiciones individuales en 1958 en el Museo Nacional, evidenciando el inicio de un nuevo periodo para el arte. La de García fue la primera muestra totalmente No Figurativa" (Alvarado-Venegas et al., 2005, p. 16).

Se reconoce así la primera labor del artista, tanto en la referencia pictórica con que inició en el medio plástico costarricense, como su posición contestataria con un arte nofigurativo. Para algunos, el trabajo se dio paralelo a estas otras latitudes, donde el arte nofigurativo tuvo tanto éxito; sin embargo, parecen no considerar que el artista conocía algunas de estas propuestas:

En 1958, Felo efectúa su primera exhibición individual en el Museo Nacional, donde presentó al público obra no figurativa que coincidía en su factura con la pintura de acción y el expresionismo abstracto de los Estados Unidos, así como con el Informalismo Europeo (Alvarado-Venegas et al., 2005, p. 8). ${ }^{3}$

Se debe reconocer que para el medio pictórico costarricense fue una propuesta no solo novedosa, sino necesaria como forma rupturista dentro del proceso pictórico nacional.

Además, se considera que la obra de García no se puede clasificar únicamente en un estilo, pues el pintor se ha dedicado a gran cantidad de técnicas y formas plásticas, las cuales han enriquecido su trabajo como pintor. Sobre esto, Zavaleta-Ochoa (1994) indica: "Paralelamente a las dos obras antes mencionadas, García desarrolló la abstracción

\footnotetext{
${ }^{3}$ En cuanto al término action painting o pintura de acción en español, se comprende como una forma de ejecución libre de la pintura artística, en otras palabras: "Técnica y estilo pictórico popularizado por Jackson *Pollock en el que se dejan caer gotas, salpicaduras y chorreones de pintura sobre el lienzo, que a menudo se encuentra extendido sobre el suelo en lugar de en posición vertical" (Chilvers, 1995, p. 25).
} 
caligráfica y gestual del informalismo o, si se quiere, del 'action painting' (pintura de acción)" (p. 38). No obstante, se debe contemplar que el trabajo plástico del expresionismo abstracto presenta, como característica particular, el hecho de que se manifestaba de diversas formas. Esto lo hace saber la estudiosa e historiadora del arte Ana Mercedes González Kreysa (2007), cuando explica el surgimiento de dicha tendencia: "Dentro de este contexto surge lo que conocemos como el Expresionismo abstracto, una manifestación mayormente pictórica que encierra dentro de su mismo nombre a varias tendencias” (p. 173). Es particular relacionar la labor pictórica tan variada de García con dicha tendencia, y observar un desarrollo similar en cuanto a lo heterogéneo del estilo.

Se considera prioritariamente su obra no-figurativa -comprendida entre las décadas de los sesenta y setenta- dentro de la forma plástica del expresionismo abstracto, con el interés de examinar la obra Ola creciente $^{4}$ de este artista, como paradigma de dicho estilo en el país.

\section{Acercamiento teórico-metodológico: Semiótica y arte abstracto}

Para estudiar la pintura de Felo García es fundamental un análisis semiótico (análisis de los significados) como acercamiento teórico a su obra. Para tal efecto, se realiza un estudio de la obra a nivel sintáctico, analizando las unidades básicas de sentido, es decir, el signo tal que significante en relación con su significado, con otros significantes y sus significados, generando en su combinación un solo concepto o entendido:

Dentro de este nivel se analizan las relaciones de los signos entre sí. En cuanto que los signos son entidades abstractas compuestas por el significante (clases de señales) con su significado (clase de mensaje) las relaciones entre signos podrán

\footnotetext{
${ }^{4}$ Ola creciente, técnica mixta sobre madera. 1967. $122 \mathrm{~cm}$ x $244 \mathrm{~cm}$. Colección del artista.
} 
ser abordadas también desde una doble perspectiva: a) la combinación de entidades conceptuales (dimensión semántica) y b) la combinación de elementos de expresión que son clases de elementos perceptibles por los sentidos físicos (visual, auditivo, táctil, etc.) (Talens, 1999, p. 58).

Como se observa, el nivel sintáctico queda fuertemente relacionado con el nivel semántico, al producirse una traslación del significante al significado, sobre todo al brindar sentido a la obra: "Quiere esto decir que la separación semántica-sintaxis es pura y exclusivamente terminológica y de metodología, pues ambas regiones están imbricadas" (Talens, 1999, p. 58). Este es el segundo nivel de análisis de la obra, específicamente sus significados:

Este nivel semántico nos es ofrecido de modo implícito por el texto mismo, en la medida en que la selección de signos, su combinación, etc. constituye un sistema de creencias acerca de la realidad que puede estar o no en contradicción con lo que explícitamente el autor asuma como suyo, pero que es, en definitiva, el campo que nos interesa para el análisis. Ya hemos dicho y repetido con anterioridad que no importa tanto lo que un artista diga que quiere decir o hacer cuanto lo que realmente dice o hace (Talens, 1999, p. 54).

De esta manera, se muestran los significantes en relación con su significado, lo cual permite esclarecer y entender de la obra en una lectura connotativa y no solo denotativa. En este sentido, sería posible asirse de los insumos necesarios para realizar una lectura contextual de la obra e interpretar el contexto que la rodea, lo cual pertenece al tercer y último nivel, el pragmático, comprendido como:

Dentro de este nivel se integran por una parte aquellos elementos que remiten a la relación autor/obra y a la correspondiente obra/lector, y por otra la referida al lugar 
de inserción de ambos, como sujetos de una práctica significante, dentro del conjunto de prácticas que constituyen una formación social (Talens, 1999, p. 47).

De esta forma, se interpreta el fin del expresionismo abstracto de García como representante abstracto de la plástica costarricense de 1970.

Por su parte, para lograr un análisis cuidadoso de la obra Ola creciente como expresionismo abstracto, se requiere establecer el concepto de abstracción. El arte debe ser entendido como creación conceptual y no solo estético-material, como propone Gillo Dorfles en la introducción al libro El arte hoy: del expresionismo abstracto al nuevo realismo, de Edward Lucie-Smith (1983), cuando de manera general expone:

El arte de todos los tiempos, por lo demás, había conservado y exaltado siempre su función cognoscitiva (y no sólo ornamental), había puesto las bases de una visión del mundo teocéntrica o antropocéntrica, en la que el arte mediaba entre el objeto y el concepto, entre los datos sensoriales y los datos mentales (p. 6).

A partir del fragmento anterior, se comprende el arte no solo como elemento estético sino como ideológico, ya que funciona como un sistema de comunicación en la práctica de la sociedad respecto a lo cultural, donde la forma está sometida a la idea de modo similar. En el arte abstracto, la estética pierde sentido como representación y responde solo a entendidos plástico-conceptuales.

Según Karl Ruhrberg y Klaus Honnef (2005), el arte abstracto tiene sus primeros acercamientos con el suprematismo ${ }^{5}$ y el constructivismo ${ }^{6}$ rusos, pues en estos se vislumbra la interpretación de la obra de arte como forma, sin importar su representación:

\footnotetext{
${ }^{5}$ El concepto refiere al abstraccionismo pictórico en Rusia, este se interesa por la representación más pura de las formas básicas del arte. Para Ian Chilvers (1995) el suprematismo se entiende como un "movimiento de arte abstracto ruso, lanzado por *Malevich en 1915. Sus cuadros suprematistas fueron las obras abstractas más radicalmente puras creadas hasta la fecha, pues se limitaron a formas geométricas simples el cuadrado, el rectángulo, el círculo, la cruz y el triángulo- y una reducida gama de colores; tras depurar al máximo sus ideas en una serie de cuadros de un cuadrado blanco sobre fondo blanco (h. 1918), dio por concluido el movimiento" (p. 921).

6 Al igual que el suprematismo, el constructivismo es un estilo artístico que se enmarca dentro del abstraccionismo y que es de origen ruso. Chilvers (1995) lo considera como un "movimiento artístico ruso
} 
Malevich ha pasado a la historia del arte como el iniciador del suprematismo. Este extraño neologismo quería expresar un objetivo muy simple: el de dar la supremacía a los medios básicos del arte, el color y la forma, sobre la mera representación de fenómenos del mundo visible (p. 162).

De este modo, Ruhrberg y Honnef presentan a Kasimir Malevich como uno de los precursores de este tipo de arte y, a la vez, delimita el pensamiento de la abstracción como ese arte que se aleja de la representación real y da prioridad a los elementos artísticos de la pintura.

Si bien la abstracción es entendida como no-figuración, pues no busca la interpretación de figuras concretas de la realidad, sí se contempla como una representación que da prioridad a los elementos y principios artísticos de la pintura: la mancha, el color y la forma básica. Por lo tanto, la abstracción de la realidad remite a esta en la medida que la semeja, aunque no de manera exacta y precisa. Umberto Eco (1997) plantea estas dos formas de interpretar la semejanza de las cosas:

Resulta indiscutible que los seres humanos piensan (también) en términos de identidad y semejanza; pero también es cierto que, en la vida cotidiana, sabemos generalmente cómo distinguir entre las semejanzas relevantes y significativas, por un lado, y las semejanzas ilusorias y fortuitas, por otro (p. 59).

Por esto, si la abstracción no busca una representación de semejanzas relevantes y significativas, sí consigue, indirectamente, una re-presentación ilusoria o fortuita con formas y colores, no figurativos, pero sí referentes a la realidad. Sobre estas discusiones, Eco (1997) explica por qué pensamos en términos de identidad y semejanza: “Actuamos así porque cada uno de nosotros ha introyectado un principio indiscutible, a saber, que,

basado en la abstracción geométrica, fundado hacia 1913 por Vladimir *Tatlin. A él se le unieron los hermanos Antoine *Pevsner y Naum *Gabo, que en 1920 publicaron su Manifiesto Realista, en el que una de las directrices era «Construir» el arte: de ahí deriva tal denominación” (p. 221). 
desde cierto punto de vista, cualquier cosa tiene relaciones de analogía, contigüidad y semejanza con todo lo demás" (p. 59). Con lo anterior queda claro cómo la pintura abstracta, como objeto real, remite a otra cosa en tanto que sus particularidades generan relaciones de analogía con el mundo visual conocido, es decir, cualquier cosa remite a otra por una relación de analogía.

En la misma línea, los conceptos anteriores son desarrollados por Ana Mercedes González Kreysa, en Historia general del arte (2007), donde explica la definición para tendencias no figurativas:

Según los teóricos del arte no figurativo como el francés Michel Seuphor, un término como el de "abstracto" para adjudicárselo a una obra que no corresponde a la imitación de la realidad es incorrecto porque, ciertamente, toda obra de arte es una "abstracción de la realidad" al ser una recreación no necesariamente fiel de lo imitado del medio natural. De ahí que el término más adecuado para designar el arte no figurativo sería precisamente este último o de arte no-objetual. Pese a ésto, a fuerza de la costumbre convencionalmente se conoce a este tipo de manifestación como arte abstracto (p. 123).

Es necesario asimilar el concepto de arte abstracto como esa no-semejanza con la realidad figurativa (semejanzas relevantes) (función simbólica de determinadas representaciones), pero sí al contemplar la imagen plástica como referencia de la realidad visual (semejanzas fortuitas) (representación de la realidad misma). Sin embargo, se utiliza el término arte abstracto, pues, como explica González-Kreysa (2007), es un convencionalismo. Igualmente, se recurre al término no-figuración, por su relación con la obra pictórica, como representante de la realidad visual no-referencialidad inmediata, de la que habla Eco. Por lo tanto, se puede entender el sentido de no-figuración, arte noobjetual o abstraccionismo, como iguales en la interpretación conceptual del término. 


\section{Contexto socio-histórico del fin de la pintura no-figurativa: $I$ Bienal Centroamericana de Pintura}

Si, por un lado, las dificultades políticas de los países vecinos afectaron parcialmente a Costa Rica, por otra parte, el proceso de globalización tuvo repercusiones sociales de gran significación, como fueron las propuestas a nivel local. Estas condiciones implicaron consecuencias en la esfera cultural costarricense, las cuales iban en detrimento del carácter artístico que se había logrado hasta entonces. Esto lo hace saber Guardia (2008) cuando se refiere al contexto de 1970:

Para la década de los años setenta, nuestro país parece haber caído en la trampa de la globalización y algunos gobiernos olvidaron la importancia de las políticas artísticas y culturales que le han conferido superioridad a nuestra Nación. El aporte privado a las artes, que ha sido importante y ha contribuido a la revitalización de este, también sufre el embate de la globalización (p. 52).

El fenómeno de la globalización repercutió en Costa Rica para la década del setenta, y tuvo consecuencias en el nivel cultural del país. Este es el paisaje nacional donde se enmarcó la I Bienal Centroamericana de Pintura, la cual fue un acontecimiento en el país que involucró a gran cantidad de artistas nacionales, quienes verían un veredicto poco satisfactorio para Costa Rica.

La obra pictórica costarricense de aquel entonces se encuentra fuertemente ligada a las tendencias abstractas europeas. Esto influyó en el veredicto de la I Bienal; así como la ausencia de un asidero temático relacionado con los problemas contextuales del territorio centroamericano en general que, si bien no afectaban directamente a Costa Rica, sí fue un hecho que medió en la decisión del jurado. 
El estudioso del arte costarricense, José Miguel Rojas, evidencia el hecho irrefutable de un cambio en la plástica nacional. De tal modo, se entiende el fenómeno de la I Bienal como factor que dio fin a la abstracción en la plástica costarricense.

Finalmente, es conveniente entender el contexto cultural de esta I Bienal Centroamericana de Pintura dentro del país. Este evento marcó grandes cambios, ya que la pintura no solo se vio en los límites finales de la no-figuración, sino que, a su vez, se presentó ante una nueva forma de representación en la obra pictórica nacional.

Así como en la década de los años sesenta proliferaron los certámenes, las exposiciones internacionales y las becas, lo cual fue un aliciente para los artistas y su inserción en las corrientes de vanguardia, la promoción y el impulso que se le dio al arte en el nivel oficial y privado, en la década de los años setenta, provocó cambios en el ambiente artístico que repercutieron a corto y mediano plazo. Las terceras vanguardias se abren camino, también la pugna entre dos corrientes plásticas: lo figurativo y nofigurativo (Guardia, 2008, p. 48).

De esta manera, queda claro cómo la década de 1970, dentro del panorama de la $I$ Bienal Centroamericana de Pintura -y a pesar de los problemas socio-políticos que atravesaba el resto de la región-, significó para la plástica costarricense una paradoja. Esto dado que los hechos socio-culturales implicaban no solo un fin de la no-figuración, sino que provocaban el debate entre esto y una nueva forma pictórica, surgida como consecuencia del fin de la primera.

\section{Análisis semiótico-pictórico del expresionismo no-figurativo costarricense con Ola creciente (1967)}

Inicialmente, es necesario comprender qué se entiende por expresionismo abstracto, a nivel histórico, esto para establecer la base sobre la cual se forja la obra 
pictórica de García. En el Diccionario de estética de las artes plásticas se entiende por expresionismo abstracto:

Nombre que se dio a una corriente pictórica, que tuvo una enorme difusión e influencia durante la década de 1950, surgida en Europa bajo la influencia del surrealismo, del "tachismo" (Ver) y de la obra de Kandinsky, adquirió un furor en Estados Unidos, especialmente en la costa Oeste, donde los artistas estaban ávidos de novedades a fin de poder sustraerse del fatigante lastre pictórico pseudoclasicista anterior (Fernández-Chiti, 2003, p. 216).

Reconocer este estilo no-figurativo en el contexto europeo permite identificar las diferencias temporales, así como la influencia que para García significó conocer otras latitudes.

El arte no-figurativo expresionista manifiesta características particulares, muy diferenciadas entre estilos como la abstracción geométrica o el informalismo. Para Kirchner, uno de los fundadores del grupo abstracto Die Brücke, los elementos plásticos de la pintura son los que brindan al pintor la capacidad de transmitir sensaciones y experiencias subjetivas:

La pintura es el arte que representa en un plano un fenómeno sensible. El medio de la pintura es el color, como fondo y línea. El pintor transforma en obra de arte la concepción sensible de su experiencia. Por medio de un continuo ejercicio aprende a usar sus medios. No hay reglas fijas para estos. Las reglas para una obra sola se forman durante el trabajo, a través de la personalidad del creador, la manera de su técnica y el tema que se propone. Estas reglas se pueden captar en la obra terminada, pero nunca se puede construir una obra basándose en leyes o modelos (De Micheli, 1993, p. 290). 
Una característica particular que resalta Kirchner es el hecho de que la obra se realiza de manera libre; es decir, no median reglas para la creación pictórica. Todo surge como una manifestación personal y subjetiva por parte de la percepción del pintor, tanto la forma técnica como temática.

En este sentido, se entiende el expresionismo abstracto como un estilo pictórico de postguerra, surgido en Europa e influenciado por el surrealismo. Asimismo, este brinda gran protagonismo a las formas plásticas como la pincelada, el color, la mancha y el grafismo, con las cuales se busca una representación subjetiva, alejada de las reglas clásicas de composición; es decir, es contraria a los postulados de la academia.

Según lo anterior, se determina que la obra Ola creciente se clasifica dentro de este movimiento pictórico, debido tanto a sus características formales como al hecho de que en esta prima la expresividad sobre la forma y el contenido. La curadora de arte Elizabeth Barquero, al describir las particularidades de algunas de sus pinturas, establece que:

Ola Creciente (Lám. 18), en las que el deseo de expresión está por encima de la forma y en las que se unen la gran riqueza del color con una forma de expresión completa y la espontaneidad de la mancha, logrando una fuerte vida interior que se proyecta sobre el lienzo, liberada de la representación. Aparece entonces una obra significativamente bella, con un valor por sí misma, aunque al mirarla aparentemente no represente nada. El espectador encuentra su significado con el título (Alvarado-Venegas et al., 2005, p. 32).

Por otra parte, como expresa Barquero, la pintura halla su significado al referenciarla con el título. La obra de arte no-figurativa no se puede considerar totalmente a-referencial. Por lo tanto, analizar este paratexto (título) como primer acercamiento al significado de la obra pictórica es fundamental para lograr una clara interpretación de 
esta, su estilo y su contexto. De este modo, se develan así los últimos rasgos de la abstracción pura en el país, antes del retorno a formas pictóricas nuevamente figurativas, y se establecen con claridad las particularidades del fin del expresionismo abstracto costarricense.

Ola creciente se valora a partir del término Ola como "onda de gran amplitud que se forma en la superficie de las aguas" (Real Academia de la Lengua Española, 2001, p. 1097). Al agregar a esto creciente, se entiende esa onda marina que está en aumento. Esto tendría su equivalente, en el cuadro, con los signos plásticos, los cuales se entenderán como los proponen Alberto Carrere y José Saborit (2000):

La pintura presenta signos pictóricos diversos y unidades de diferente dimensión («pinceladas», «manchas», «colores», «formas», «representaciones», «pedazos de tela», o de «papel», el propio «cuadro»...), que pueden llamarse propiamente así, signos pictóricos, en la medida en que manifiestan una dimensión sémica, es decir, en la medida en que, de manera general, muestran que algo está en lugar de algo para alguien, siendo su parte material (expresión) capaz de evocar alguna otra $\operatorname{cosas}($ p. 73).

Por lo tanto, los colores azul, rojo y blanco, donde el azul se interpreta fácilmente como agua y el blanco como la espuma del mar al reventar la ola; esto sobre todo al estar representados por manchas curvadas. No obstante, una lectura más profunda y simbólica brinda una visión completa del trabajo pictórico. Por esto, se puede estudiar la Ola como la interpreta Chevalier (1986) en su Diccionario de símbolos:

Las olas levantadas por la tempestad han sido comparadas también a los dragones de las profundidades. Simbolizan entonces las irrupciones repentinas de lo inconsciente, otra masa de orden psíquico, de engañosa inercia, lanzada por las pulsiones instintivas al asalto del espíritu, del yo pilotado por la razón (p. 774). 
Con esto se connota un sentido inconsciente-subjetivo en la representación (orden psíquico). Como menciona el autor, son pulsiones instintivas del espíritu (del yo), donde, al igual que el enfoque expresionista abstracto, la obra tiene un sentido liberador de las formas plásticas, al igual que la libre creación de la pintura.

Si a este sentido inconsciente de la Ola se aúna la simbología del color azul, se logran hacer más asociaciones de orden subjetivo. Como propone Chevalier (1986), al referirse al entendido que tenía el pintor abstracto Kandinsky:

Su movimiento, para un pintor como Kandinsky, «es a la vez un movimiento de alejamiento del hombre y un movimiento dirigido únicamente hacia su propio centro que, sin embargo, atrae al hombre hacia lo infinito y despierta en él deseo de pureza y sed de lo sobrenatural»(KANS). Se comprende entonces su importante significación metafísica y los límites de su empleo clínico (p. 164).

Surge aquí una connotación del azul como un deseo de pureza, similar a lo estudiado con Blanco interrumpido y el arte abstracto geométrico, pero esta vez da prioridad a su sentido subjetivo.

Es posible asimilar el color rojo presente en las manchas curvas que semejan las olas como un elemento de cambio. A pesar de que el rojo se asocia con tantas connotaciones: "El color activo y masculino de la vida, fuego, guerra, energía, agresión, peligro, revolución política, amor, alegría, festividad, vitalidad, salud, fuerza y juventud" (Tresidder, 2003, p. 204), es indistintamente vinculado con signos de vigor y energía. Razón por la cual puede simbolizar con mayor fuerza el cambio positivo: "Rojo es el color del fuego que todo lo purifica, o del amor que todo lo sublima" (Deneb, 2001, p. 241). Además, el color rojo se vincula con esa transformación en la obra, el cambio de lo quieto a lo activo, la energía y la sublimación-purificación de la Ola. 
Al entender la obra como una manifestación técnica y conceptual surgida de pulsiones instintivas del espíritu, y vincular esta con la simbología de cambio y purificación (significación metafísica), es posible observar cómo no solo se connota una relación subjetiva en la obra, sino que se posibilita la denotación de referentes visuales reconocibles, a través de los signos pictóricos. En este sentido referencial de los signos pictóricos (plásticos) de una obra no-figurativa es necesario aclarar que, como explican Carrere y Saborit (2000), ante el hecho de que se suele identificar signo icónico con pintura figurativa (representativa) y signo plástico con la pintura abstracta, esto se considera un error, pues "el signo no es una entidad fija, sino una convención que provisionalmente relaciona expresión y contenido, de modo que signo plástico y signo icónico pueden producirse a partir de un mismo plano de la expresión” (p. 91). Es decir, un signo plástico puede significar de forma similar (no igual) que lo haría un signo icónico. Por lo tanto, en la obra Ola creciente es posible el vínculo título-imagen como referente visual reconocible.

Esto es aún más comprensible cuando la historiadora del arte, Eugenia Zavaleta Ochoa (1994), habla sobre las características de Ola creciente y considera en estas el chorreo, los trazos gestuales y la pincelada libre, como rasgos particulares que se relacionan con el título de la obra. Al respecto, hace una descripción donde vincula el paratexto con el texto:

Lo anterior se hace más evidente en Ola creciente (1967) (Lámina \# 18). El artista produjo toda una imagen, reforzada con el título, al disponer de una serie de trazos diagonales o curvos en blanco, rojo y negro. Estos definieron la sensación ascendente que conduce al punto culminante antes de que la ola reviente. También se valió de las delicadas líneas blancas, que evocan el agua espumeante, para 
anunciar la inminente caída de la onda marina. Y, por último, con los acertados acentos rojos, ayudó a crear un fuerte contraste y a equilibrar la pintura (p. 80).

En este estudio plástico que hace la historiadora, se observa ese vínculo que logran los signos plásticos como isotopías del mensaje visual; es decir, cómo los formemas, cromemas y texturemas (manchas, pinceladas, líneas y colores) logran generar una sinécdoque plástica. Este término aplica si se considera que:

La elipsis en lo plástico, por ejemplo la elipsis de textura y color por medio del recurso del dibujo (cap. III, § 3.5.4.), puede implicar simultáneamente una sinécdoque plástica en lo icónico, por cuanto una parte de los elementos constituyentes del signo plástico está por todas las demás (Carrere y Saborit, 2000, p. 325).

Se interpreta esa no-figuración de los elementos plásticos en conjunto como una figura referencial a través de un desvío forma-contenido; o sea, la parte -manchas y colorpor el todo -ola, agua y mar-, sobre todo al vincular estos con una imagen visual reconocible, una ola a punto de reventar, una onda marina y sus aguas espumeantes.

A pesar de que el expresionismo abstracto se caracteriza por una libre creación, alejada de reglas fijas, la pintura, como menciona Zavaleta-Ochoa, logra equilibrarse a través de contrastes con algunos acentos rojos, lo cual refiere cierta planificación de la obra. Al respecto, se puede comprender cómo la pintura en estudio, a pesar de estar calificada dentro de dicha tendencia -por el uso de chorretes y trazos gestuales-, se crea bajo ciertos paradigmas compositivos que alejan su creación del automatismo característico del expresionismo.

La historiadora del arte deja clara esta postura sobre la racionalizada creación de la pintura cuando explica que, en algunas de las obras de García (de las cuales Ola 
creciente es más característica), es posible observar el estudio que el artista realiza, cuidando el contraste, el equilibrio compositivo y la armonía:

A pesar de que en este tipo de obras predomina lo emotivo, en García prevaleció y rigió el diseño racional y muy meditado. Esto se aprecia en cómo utilizó el rojo y el azul para crear una armonía por contraste y para equilibrar el cuadro, o en cómo plasmó un delicado y transparente "dripping" para también equilibrar y, a la vez, contrastarlo con los vigorosos trazos (Zavaleta-Ochoa, 1994, p. 80).

No solo se establece el trabajo plástico de tendencia expresionista abstracto por sus características plásticas, sino que se diferencia de este estilo de manera particular (pues la obra es estudiada y planeada). Sin embargo, se debe considerar que la mancha y el dripping brindan a la obra esa espontaneidad que surge fortuitamente por el derrame de pintura.

Asimismo, es necesario contemplar la labor del pintor para comprender la repercusión de esta experiencia sobre la pintura en estudio. Para algunos estudiosos, la pintura del artista es claramente de tendencia expresionista abstracta, por el trabajo expresivo-subjetivo con que sugiere sus creaciones, recurre a técnicas y elementos pictóricos que evocan la libre creación del trabajo pictórico. Tal es el caso de la estudiosa Yamileth Pérez (2009), quien perfila el desarrollo artístico de las obras de García como espontaneidad creadora, sin trabajo de boceto:

Su etapa inicial fue eminentemente arte abstracto, luego pasó a la etapa -al parecer experimentada por más tiempo-, acerca del goce por el color y la forma, en cuyo proceso prevaleció la espontaneidad creadora, pintando directamente sobre el lienzo, sin intermediación de boceto alguno (p. 77).

La ausencia de no boceto o dibujo demuestra una falta de planificación en la obra, y podría determinarse que la pintura es completamente autónoma e indeliberada. Empero, 
a pesar de la influencia en el extranjero de un expresionismo abstracto libre y espontáneo, la propuesta de García, en Costa Rica, se vuelve particular. El artista la proyecta en forma controlada, como manifiesta Guillermo Montero (historiador del arte y exdirector del Museo de Arte Costarricense):

El tipo de pintura que hacía en los 60 estaba muy influido por el New Vision Group, la comunidad artística de la cual formó parte en Inglaterra en los 50. También recibió el influjo de la action painting, que se desarrollaba en los Estados Unidos. Sin embargo, a diferencia de este estilo, su pintura nace de un efecto más controlado (Chinchilla-Ugalde, 2009, párr. 14).

Igualmente expresiva, su pintura no obedece radicalmente las posturas extranjeras de la no-figuración expresionista; se propone como un expresionismo no-figurativo costarricense.

La obra Ola creciente no solo responde a un expresionismo abstracto para Costa Rica, sino que establece una relación entre el título y la imagen, a través de la cual se logra una representación clara para el espectador, como describe la pintura Eugenia Zavaleta Ochoa: blanco de espumas y olas reventando.

Esta imagen clara de la obra abstracta que logra representar algo, esta nofiguración que no puede ser a-referencial es una característica de las obras pictóricas del artista, pues como explica Elizabeth Barquero, la obra de García (entre 1956 y 1958) inicia como una voluntad de estilización y esquematización, en la cual:

El resultado final es una abstracción, pero la presencia de la realidad persiste a lo largo del proceso. La realidad es transformada por el creador, pero este no reniega de ella. En algunos casos, constatamos la contracción de la forma hasta concluir en el signo. Para los espectadores actuales el valor primitivo del signo desaparece y es reemplazado por un orden estético" (Alvarado-Venegas et al., 2005, p. 32). 
De esta forma, es posible denotar la expresividad de la obra, la carga subjetiva de su creación. Pero, a su vez, se vincula la obra con procesos creativos compositivos que connotan la referencialidad de esta, así como en Ola creciente, al pertenecer a dichas formas de creación.

A pesar de que se puede demostrar cierta referencialidad en la obra, esta no puede tomarse en forma categórica, pues indiscutiblemente la propuesta en Ola creciente evoca la expresión y libertad creativa; es decir, el referente no es exacto con la realidad, es solo parcialmente afín. Por eso, cuando Alcaide-Ramírez (2010) habla de la Taxonomía de los cuadros abstractos aplicando el criterio de su grado de realidad, se refiere a la capacidad de representación de las pinturas de tipo no-figurativo. Para esto, plantea diferentes grados de referencialidad de las obras de esta tendencia. Como se estudió, la obra de Blanco interrumpido pertenece al primer grado o pura; en el caso de Ola creciente, se puede clasificar en el 2. ${ }^{\circ}$ grado, como la misma estudiosa expone:

Un cuadro abstracto pertenece al grupo de la Abstracción de $2^{\circ}$ grado cuando en él no hay referencias formales al mundo exterior del artista, aunque sí a su naturaleza interior. El aspecto visual del mismo, al igual que su proceso de realización serán muy distintos, en función de si el artista utiliza el cuadro como vehículo para expresar sus emociones y sentimientos o para explorar los confines de su espíritu y de su razón, y así poder ofrecer una versión metafórica de la esencia del universo, de lo inmutable y que no puede ser aprehendido por los sentidos, sino mediante el intelecto, y que constituye realmente lo que puede ser calificado como Belleza Perfecta, el Bien Supremo o Dios, según las teorías platónicas (1969: 12-38) (p. 17).

Según este criterio de clasificación de la capacidad de representación de las obras no-figurativas, Ola creciente se toma como vehículo para expresar emociones y 
sentimientos, con lo cual ofrecer una versión metafórica de la esencia del universo, y, por ende, establece una búsqueda por la Belleza Perfecta-el Bien Supremo. En este sentido, se vincula la obra Ola creciente de García con Blanco interrumpido de González-Kreysa, por esa búsqueda de la perfección (al enlazar el significado del azul como búsqueda de la purificación y del rojo como elemento de cambio), o sea una realidad paralela al mundo donde se vive.

Este planteamiento, donde se separa la realidad de la pintura y se busca con esta última una realidad más bella y pura, es expuesto por Barquero cuando menciona la relación entre la obra del pintor y el arte abstracto:

Felo García, inquieto, creativo, se deja subyugar por esta forma de expresión, en la que, mediante un proceso mental, se separa la realidad del realismo y construye una nueva realidad. Adopta una forma diferente de comunicación, subjetiva al más alto nivel, cuya significación se sustenta en la lectura de formas, la combinación de colores y el contraste de textura" (Alvarado-Venegas et al., 2005, p. 30).

Con esto, se interpreta la obra como la construcción de una realidad alterna ( $\sin$ renegar de la realidad misma), que aunado a lo que propone Alcaide-Ramírez, constituye el Bien supremo. Esto se hace aún más significativo al relacionarlo con la simbología del color rojo como ese elemento que todo lo purifica, por su efecto de sublimación, así como con el azul en tanto deseo de purificación.

Hasta aquí es posible considerar cómo la obra pictórica Ola creciente de García se establece dentro del estilo expresionista abstracto. Asimismo, se distingue una lectura clara entre imagen y paratexto, con la cual establecer la particularidad del expresionismo no-figurativo costarricense, el cual no solo es expresivo y subjetivo, sino que está planeado, o sea, no es un arte totalmente aleatorio. Incluso, se observa que esta obra, programada, connota la intención de una nueva realidad, que refleja la bella sutileza de la 
mancha y la pincelada, dispuestas según una organización de color en el espacio compositivo.

Este vínculo entre la pintura, como realidad alterna que busca la belleza y perfección, con el trabajo Blanco interrumpido de González-Kreysa, tiene cierto sentido cuando se valora el hecho de que estas tendencias de los artistas eran construcciones plásticas que ambos habían conocido fuera del país. Así, manifiestan cierto paralelismo con los cambios que estas artes habían tenido en el extranjero:

El desarrollo del arte abstracto después de la guerra partió de una objetivación purista basada en la forma calculada matemáticamente, pasando por un reino autónomo de signos llenos de recuerdos de la naturaleza, para llegar finalmente a una representación de sentimientos y sensaciones subjetivas, reflejos mentales de las experiencias de la realidad del artista: un arte expresionista abstracto, en pocas palabras, que culminó en l’art informel en Europa y en action painting en Estados Unidos (Ruhrberg, 2005, p. 231).

Sin embargo, a nivel nacional, este tipo de proceso no se da de manera progresiva, sino, por el contrario, de modo simultáneo. Lo anterior se debió a que, al tiempo que con Blanco interrumpido González-Kreysa realizaba obra abstracto geométrica (forma calculada matemáticamente), con Ola creciente García proponía su labor del expresionista no-figurativo.

La influencia extranjera en la pintura abstracta de Costa Rica la presenta TrianaCambronero (2013) al referirse al lugar de procedencia de cada una de estas formas estéticas, a través de la influencia de sus autores (es necesario considerar este proceso de los artistas para comprender cómo incide sobre la pintura):

Estos tres creadores que mencionamos habían regresado del extranjero no hacía mucho: Fernández venía desde Italia, González de Venezuela y García de 
Inglaterra. No fue azaroso que cada uno de ellos estuviese inmerso en el mundo del arte no representativo pues la abstracción había tomado ya gran fuerza en aquellos países (párr. 5).

Es significativo valorar no solo la reminiscencia de estos artistas en el extranjero, sino considerar el contexto artístico fuera de Costa Rica, en relación con el que se daba en el país.

Para Vargas-Durán (1999), el ambiente costarricense se encontraba en un contexto plástico muy diferente al de países europeos, y, en parte, debido a esta descontextualización, las primeras exposiciones de arte abstracto padecieron la crítica, como todo aquello que es nuevo y desconocido: "El choque fue terrible en este paraíso donde la última aventura plástica era pintar a la manera impresionista, las exposiciones sufrieron una pésima acogida como la atestiguan artículos del diario La Nación y la Prensa Libre” (párr. 9). Esta propuesta novedosa para el ambiente cultural en Costa Rica se plantea como rupturista, pues venía a contrariar los cánones de la academia, así como las propuestas pictóricas tradicionales.

La realidad contextual de Costa Rica y su ambiente artístico difería en relación con el panorama que se generaba en el exterior, este contraste se evidencia en ZavaletaOchoa (1994) cuando menciona que "a finales de 1956, Felo García regresó a Costa Rica con un horizonte más amplio, el cual quizo mostrar a sus compatriotas. Pero lo que encontró fue un ambiente plástico 'miserable”" (p. 23). En relación con esta problemática, el artista decidió actuar de inmediato; trabajó hasta mostrar en 1958 lo que se ha considerado como la segunda expresión de arte no-figurativo. Para la historiadora, las exposiciones de los artistas abstractos en el país generaron gran cantidad de crítica: "Toda esta situación de expresiones de disgusto de unos y de complacencia de otros, evidencia que se estaba gestando un cambio en la plástica costarricense" (p. 25). Esto no solo 
reafirma el cambio en la pintura tradicionalista en el país, sino que permite vislumbrar esa ruptura con el academicismo de la plástica nacionalista. Surgió un cambio en la forma de pintar, donde la mancha y la libre pincelada tomaron protagonismo, junto a colores intensos, así como el rojo de Ola creciente, símbolo de cambio y sublimación.

La discordia entre los estilos plásticos del país permite observar un paralelismo con el surgimiento del expresionismo abstracto europeo, el cual se propone como elemento reaccionario contra las doctrinas establecidas para la época: "El expresionismo abstracto constituye una reacción contra los modos de sentir más mezquinamente nacionalistas" (Lucie-Smith, 1983, p. 49). Esta particularidad del estilo refleja el sentido que tiene el uso de la no-figuración, como elemento de diferenciación con los otros movimientos artísticos, ya que busca reaccionar ante lo conocido por un efecto de oposición.

Al igual que en el extranjero, la forma como se acogió la pintura abstracta en el país reflejó no solo el carácter tradicionalista con que se interpretaba el arte pictórico, sino que demuestra cómo este funcionó como ruptura, ante el panorama artístico de la Costa Rica de los sesenta y setenta.

En cuanto al expresionismo en sí, este surge como reacción contra las ideologías del momento en los países europeos de inicios del siglo XX. El positivismo con que se trataba de ver el mundo ante la eminencia de la guerra provoca en los artistas una repuesta contestataria y de oposición:

El expresionismo nace sobre esta base de protesta de crítica y es, o pretende ser, lo opuesto al positivismo. Se trata de un amplio movimiento que difícilmente se puede encerrar en una definición, o delimitar según la forma en que se manifiesta, como se podría hacer en otros casos, por ejemplo, el cubismo. En efecto, los modos en que el expresionismo se manifiesta, incluso si queremos agruparlos a 
grandes rasgos, son bastantes numerosos y diversos. La única manera de llegar a su composición es, pues, partir de sus contenidos, que, por lo demás, son todos menos unívocos. De todos modos, lo que se puede decir de entrada es que el expresionismo es, sin duda, un arte de oposición (De Micheli, 1993, p. 72).

La pintura de García se estima como rupturista, desde su inicio y hasta que se contempla la obra Ola creciente, cuando se encuentra en la cúspide de su abstracción. Esta pintura se considera reveladora del trabajo pictórico del artista; esa Ola que aumenta e irrumpe, que con el rojo vaticina el cambio y con el azul promueve pureza, es un cambio en la plástica y en la mentalidad del costarricense. De igual manera, al provocar tanta conmoción en el medio costarricense y vincularse con la ideología del expresionismo abstracto-, es prudente considerar cómo estaba el medio plástico de entonces, así como determinar la relación entre obra y contexto.

Para estudiosos de la historia como Guillermo Barzuna Pérez (2005), la segunda mitad del siglo XX representa, para el acontecer costarricense, la manifestación clara de la modernidad y, con esta, de los estilos representativos de la vanguardia, aunado a una búsqueda identitaria:

La segunda mitad del siglo XX representa en el caso costarricense, un evidente auge y desarrollo de la modernidad en diversas manifestaciones artísticas. La plástica asumió a partir de los años 60 signos de vanguardia en correspondencia con otras latitudes del planeta, aunque de forma poco tardía. El vanguardismo que ha recorrido la pintura y la escultura desde el grupo de los 8 , hasta el actual grupo Bocaracá, muestra un medio siglo de arte alternativo y de búsqueda incesante en torno a la creación y afirmación de identidades (p. 3).

Con esto no solo se nota la consolidación del modernismo en la Costa Rica de los años sesenta, sino que permite vislumbrar el hecho de que la plástica, al igual que otras 
formas culturales, buscaba un sentido de identidad-como menciona Barzuna-Pérez-; con este parecer, se relaciona esta búsqueda con el hecho de que el país se encontraba en los inicios de las manifestaciones de la globalización y el capitalismo real. De tal forma, definir una identidad era significativo para posicionarse en el ámbito mundial.

Ola creciente no solo estima la influencia del artista en el extranjero, sino que permite establecer las particularidades de la vanguardia en el país. Asimismo, se ubica en un periodo en el cual el modernismo y la modernidad están perfilándose en la cultura costarricense. La obra no solo es representación subjetiva de la creatividad del artista, también es un signo evidente del acontecer nacional.

Vargas-Durán (1999) habla sobre el desarrollo de las ideas estéticas en el país como consecuencia de los planteamientos de la modernidad. Estos procesos los posiciona en los años setenta y los interpreta a través de los cambios sociales, como es el consumo de masas (resultados de la globalización). Estos acontecimientos afectan directa e indirectamente la producción artística en el país:

Con los años 70 la tecnología amplia los horizontes del rincón paradisíaco. El "santón" MacLuhan habla de la aldea global y se comienza con el arte pop, como expresión de la sociedad de masas lógicamente consumista y todo esto crea una nueva gama de artistas con intenciones de un arte que rebase las fronteras de lo nacional y se le abran las puertas a los grandes mercados internacionales (párr. $10)$.

Es así como se interpreta la acogida de la modernidad en Costa Rica, donde la revelación de procesos globalizadores hace que los artistas busquen más allá de lo que el país ofrece; esta forma de pensar comienza con la llegada de los pioneros abstractos al país, que regresan con deseos de cambiar el panorama general de la plástica costarricense. 
La propia obra de García buscaba abrir el panorama plástico a través de una pintura nofigurativa.

Los procesos de globalización tienen sus inicios con la llegada de la televisión al país: "El cambio decisivo en el consumo cultural de masas, sin embargo, ocurrió en la década de 1960, al inaugurarse la televisión en Costa Rica" (Molina-Jiménez, 2007, p. 15). Este, como medio de difusión publicitario, no solo promocionó el consumo de bienes, sino que inspiró estilos de vida foráneos: "La televisión debutó en Costa Rica en 1960, y se convirtió rápidamente en la punta de lanza de la saturación de la vida cotidiana de los costarricenses por el entretenimiento y la información procedente de Estados Unidos” (Molina-Jiménez, 2005, p. 23). La vida cotidiana, la sociedad y la cultura costarricense se ven afectadas por este acontecer, así como por los cambios generales en la región latinoamericana.

La globalización, como ese proceso de comunicación e interdependencia entre los distintos países del mundo, que presagiaba conflictos de identidad para cada una de las diversas comunidades del planeta, tiene su comienzo en Costa Rica entre los años sesenta y setenta, con cual se presentan nuevas formas de interpretar las realidades locales en contraste con otras latitudes.

La comparación de la vida cotidiana, social, económica y cultural, con otros parajes del planeta, tiene para el país sus comienzos con la creación de la televisora nacional, al presentar estilos de vida extranjeros. Sin embargo, es a nivel artístico donde se presagiaba esa confrontación entre lo local y lo foráneo que promovía la globalización, no solo por la importación de estilos artísticos por parte de los pintores que viajan, sino por la misma necesidad de romper con la tradición en el medio y enfrentar al país a nuevas propuestas. La estudiosa Tamara Días Bringa (2003) habla sobre la labor de los tres 
abstractos costarricenses (Manuel de la Cruz González, Lola Fernández y Felo García), y el ambiente cultural:

Ahora bien, si aquellos artistas encontraron en su momento un medio adverso a sus propuestas, de alguna forma sentaron las bases para una mejor comprensión de la abstracción en el país. Desde luego, varios años después el contexto sociocultural sería de diferente y el debate en torno a lo propio y lo ajeno, lo local y lo global se han vuelto más inestables y difusos (p. 17).

Es notable el hecho de que Costa Rica se insertaba en procesos de mundialización que afectaban el medio artístico; de igual manera, toda la región se encontraba en un proceso de avance industrial, como refiere Barzuna-Pérez (2005) sobre América Latina: "La década del sesenta es la resultante, por un lado, de los efectos de los programas populistas desarrollados desde los años cuarenta en todos los países de la región y de los procesos de industrialización" (p. 21). La industrialización y los principios de la globalización (como es el libre comercio y consumo de masas) proyectan cambios en la forma de vida del latinoamericano, por ende, del costarricense y su cultura.

Con esto, el cambio proyectado por el azul y el rojo de Ola creciente, donde se busca una realidad más pura con la no-figuración y fuera de esta realidad, se identifica con los cambios que se manifiestan en el ambiente nacional. No es que la obra represente el cambio de la vida del costarricense frente a la globalización. La pintura Ola creciente es una más de sus manifestaciones; o sea, representa los cambios en la plástica nacional, la cual busca esa internacionalización, esa proyección del costarricense frente al mundo.

Empero, es necesario tomar en cuenta no solo el panorama local, sino, a su vez, la realidad del resto de la región latinoamericana, la cual se encontraba en momentos de crisis política, económica y social, debido a dictaduras y procesos militares. Dentro de 
este panorama, las vanguardias europeas encontraron un acicate en el contexto convulso latinoamericano:

Ya a partir de los años cincuenta, aquel incipiente interés por las corrientes de vanguardia, manifestado por los artistas latinoamericanos, tomó fuerza y sus adherentes proliferaron. Las miradas se volvieron hacia las tendencias que en ese momento ocupaban a los creadores plásticos europeos y estadounidenses, es decir, el expresionismo abstracto, la abstracción geométrica y el arte cinético (ZavaletaOchoa, 1994, p. 167).

Esto se debería a la fuerza expresiva de la no-figuración, la explosión de colores y manchas que se enlazan con representaciones de posguerra. Cual sea la interpretación, lo cierto es que, como afirma la crítica de arte Marta Traba (1994): "En el apogeo de las dictaduras latinoamericanas durante las décadas 50 y 60 el expresionismo es un efectivo vehículo para canalizar mensajes políticos y sociales" (párr. 45). A pesar de esta coyuntura entre este estilo pictórico y contexto latinoamericano, la realidad del país, para los años sesenta y setenta, es diferente. El país no se encontraba en problemas militares ni en revoluciones políticas, por lo cual se asumía esa postura de que la abstracción no solo era foránea (a la plástica nacional), sino también ajena a la realidad costarricense (representación del contexto).

Pese a la ausencia de crisis política en los años sesenta, la realidad costarricense se enfrentaba en revoluciones sociales como: las protestas contra el incremento de la electricidad que, para 1962, era parte de la tradición de lucha social del Valle Central; las protestas por el agua en el proceso de centralización del Estado, donde el SNAA fue el blanco de las luchas sociales; también se da la lucha por los problemas de vivienda y enfrentamientos contra los empresarios autobuseros (Alvarenga-Venutolo, 2005, pp. 1841). Esto sin mencionar la lucha radical contra la firma del contrato con la transnacional 
norteamericana Aluminum Company Amalgamated (ALCOA) en los años setenta. Todo esto confirma un movimiento social que, si bien no es revolución político-militar, sí señala la situación turbulenta de Costa Rica en esa época.

En relación con la idea anterior, se afirma que la realidad costarricense no es del todo pacífica y, en asuntos culturales, la plástica comienza no solo a mostrar signos de vanguardia, sino a perfilar la discordia con los estilos más radicales del modernismo. La obra Ola creciente es la muestra de esa ruptura del trabajo plástico en Costa Rica, pero sobre todo es ejemplo de cómo esta plástica no-figurativa posibilitó nuevos panoramas para la pintura costarricense, volviéndose parte de la historia del arte costarricense. Para el crítico brasileño Mário Pedrosa, en Latinoamérica la ruptura dentro de formas plásticas académicas es considerada como revolución plástica:

En un texto escrito dos años después, el crítico brasileño sacará a relucir nuevamente el asunto de las relaciones entre revolución política y revolución artística, concluyendo que esta última debía entenderse sobre todo como revolución de la sensibilidad, una revolución a la que estaba contribuyendo en gran medida la difusión de la plástica abstracta (De la Nuez, 2014, p. 199).

Es decir, Costa Rica antes de la no-figuración, se encontraba en un periodo relativamente estable, no se daban grandes fenómenos políticos ni militares, como en el resto de la región centroamericana. Por su parte, la plástica nacional es descrita como adormecida y miserable; por lo tanto, el ingreso de la abstracción es comprendido como un acontecimiento de ruptura. En este sentido y ligado a lo que indica Pedrosa, si bien la revolución en Costa Rica no era de orden político, por la divergencia en la sensibilidad pictórica, como es el caso de la obra de García (y en la pintura de los otros artistas nofigurativos), sí manifiesta una revolución plástica. La no-figuración no solo generó 
ruptura, sino que al finalizar esta (con obras como Ola creciente) consigue ser admitida dentro del arte nacional como una estética que abrió posibilidades en la plástica del país: Esto, sin embargo, no disminuye ni la obra ni la contribución realizada por Fernández, García y González de introducir la abstracción en nuestro medio. Y si bien no inventaron un lenguaje plástico y tampoco el arte abstracto sobrevivió como una corriente fuerte en el país, sí abrieron el panorama pictórico costarricense a nuevas posibilidades estéticas (Zavaleta-Ochoa, 1994, p. 88).

Por lo tanto, al contemplar Ola creciente como significante, denota la sensibilidad del artista, en tanto el arte siempre es subjetivo; asimismo, con los trazos curvos de rojo y azul, connota el cambio en el movimiento del mar. También, la pintura permite distinguir la característica particular de la totalidad de la obra del pintor como elemento de ruptura en la pintura costarricense, y como medio que posibilitó nuevas formas plásticas en Costa Rica - como puede ser apreciada la neofiguración ${ }^{7}-$. De esta forma, es un ejemplo de revolución plástica que comenzaba a hacerse evidente en la región.

Finalmente, Zavaleta-Ochoa (1994) se refiere a Ola creciente como un trabajo gestual, con predominio de lo emotivo, mediante la pincelada libre, el chorreo y gracias al uso del gran formato; en suma una obra más expresiva: "Con la magnificencia brindada por estas obras de gran formato y de amplios trazos, semejantes a los últimos acordes de una sinfonía, García finalizó su trayectoria abstracta para poco después sumergirse dentro de la figuración” (p. 80). A pesar de que Rafael Ángel Felo García ha continuado trabajando obra abstracta y figurativa, es con estas características que se ha conocido su

\footnotetext{
${ }^{7}$ El concepto es utilizado desde los años sesenta, aproximadamente, y hace referencia, especialmente, a la pintura neofigurativa. Fue un movimiento artístico de la segunda mitad del siglo XX, el cual se caracteriza por representar una reacción al abstraccionismo de los años cincuenta; en este sentido, es una vuelta a la pintura figurativa pero con rasgos de los estilos informal y expresionista. Merizalde-Salazar (2013) asume el término como: "La Nueva figuración o Neo figuración fue un movimiento artístico desarrollado entre las décadas de los 60's y 70's del siglo XX, como una respuesta al contexto político (Segunda Guerra Mundial, Revolución Cubana, múltiples dictaduras militares en América Latina, entre otros) que cambiaron la concepción del cuerpo, permitiendo que se regresara a la pintura figurativa, al objeto, a la cotidianidad, pero con las técnicas del informalismo y reaccionando con respecto al arte abstracto" (p. 6).
} 
labor dentro del fin del periodo no-figurativo en el país. Asimismo, se vislumbra su inmediata labor pictórica como referencial que, en cierta medida, se podría catalogar como una obra neofigurativa dentro de su pintura.

\section{Conclusiones}

La obra pictórica de Rafael Ángel Felo García, como representación del arte nofigurativo en Costa Rica, posibilita apreciar las peculiaridades artísticas de tal estilo, así como determinar una semántica de estas, con lo cual se interpreta el contexto del trabajo pictórico. Lo anterior permite, a través de un análisis semiótico de la pintura, considerar las particularidades que dan fin al periodo abstracto en la pintura del país.

Con Ola creciente se propone una obra de carácter expresionista, esto debido a la libertad en la creación plástica con manchas, pinceladas y texturas más sueltas. Así, al examinar esta pintura, se denota la sensibilidad del artista, forjada a través de la subjetividad de García. Como significante, los trazos curvos de rojo y azul connotan el cambio -el movimiento del mar-, al igual que el cambio de la plástica nacional. A pesar de esto, el trabajo de boceteo en la obra propone una particularidad de la no-figuración costarricense, que se aleja del expresionismo convencional europeizante, pues en este no median reglas para la creación pictórica. Sin embargo, en su obra se interpreta cómo la expresividad prima sobre la forma y el contenido, con lo cual se establece el expresionismo costarricense.

La obra pictórica Ola creciente determina no solo la labor rupturista del estilo, en relación con lo que habitualmente se pintaba en Costa Rica, sino que con esta se interpreta la no-figuración en el arte nacional como una revolución plástica. Pese a que la pintura no-figurativa fue vista tanto como un acontecimiento que sucedió sin relación con el contexto nacional, como una labor peligrosa para la plástica nacional, el alejamiento de 
la pintura, no solo con la tradición pictórica sino con el mismo academicismo que se practicaba en el país, es un referente de los cambios sociales que se gestaban en Costa Rica en los ámbitos cultural, económico y político. De tal forma, se establece la particularidad del arte expresionista costarricense.

El hecho de que Costa Rica pasara de un modelo agroexportador a uno industrializado, con la unión al Mercado Común Centroamericano, fue el resultado de la expansión del consumo de masas, estimulado por la publicidad y la televisión. Esto no solo es representación del cambio económico en el país, sino que es señal de un cambio político y cultural. Costa Rica se encontraba en las puertas de la globalización, en pleno capitalismo real; asimismo, era el evidente resultado de una modernidad ya instalada. Aunado a los acontecimientos mencionados y al uso intensivo de la tecnología, el modelo industrial fracasó en el país, debido a que al generar abundante empleo, se provoca, con la primera fase de expansión urbana -que se refleja a lo largo de las principales vías de acceso al San José-, una urbanización faltante de planificación. Esta urbanización era espontánea y desordenada, pues confluían viviendas con comercios, talleres y fábricas.

$\mathrm{Al}$ respecto, los cambios se hacen notorios en la pintura no-figurativa de Costa Rica; así, la obra Ola creciente, en la cual se descubre ese cambio rupturista en la plástica costarricense, se interpreta como revolución plástica, al igual que los cambios políticos y económicos que trajo el nuevo sistema industrial.

Por ende, se observa cómo los cambios económico-políticos, con la implementación de la industria (consumo de masas, influencia de la televisión y desarrollo urbano), produjeron no solo cambios en la sociedad (movimientos sociales, poca generación de empleo y afeamiento de la ciudad), sino que, a su vez, provocaron un cambio cultural observable en la revolución plástica que significó la no-figuración en Costa Rica. Lo anterior se interpreta como la clara manifestación del modernismo en el 
país, así como la introducción de las vanguardias ante los cambios sociales y políticos de la modernidad.

Sin embargo, esta revolución plástica que significó la no-figuración terminó percibiéndose como un discurso desgastado utilizado por más de diez años que, para 1971, al coincidir con la I Bienal Centroamericana de Pintura, mostraba las señales de un arte agotado. La obra del artista no-figurativo, en los años setenta, era parte de la plástica costarricense, y su posición rupturista había dejado de significar un cambio para la academia, con lo cual pasó a incorporase a esta y a la pintura costarricense.

\section{Referencias bibliográficas}

Alcaide-Ramírez, A. (2010). Cómo mirar un cuadro abstracto: Aproximación a la abstracción pictórica mediante el análisis de obras realizadas por mujeres. Revista Creatividad y Sociedad, 15(5), 1-29. Recuperado de http://www.xtec.cat/alfresco/d/d/workspace/SpacesStore/15b5d3de-ff8f-435a80d5-164c9bd4be75/creatividadysociedad_como\%20mirar.pdf

Alvarado-Venegas, I., Barquero-Segura, E. y Quirós, F. (2005). Felo García: artista, gestor, innovador. San José, Costa Rica: Editorial de la Universidad de Costa Rica; Fundación Museos Banco Central de Costa Rica.

Alvarenga-Venutolo, A. P. (2005). Los ciudadanos y el estado de bienestar: Costa Rica en la segunda mitad del siglo XX. San José, Costa Rica: Editorial de la Universidad de Costa Rica.

Barzuna-Pérez, G. (2005). Cultura artística y popular en Costa Rica: 1950-2000 EUCR. San José, Costa Rica: Editorial de la Universidad de Costa Rica.

Carrere, A. y Saborit, J. (2000). Retórica de la pintura. Madrid, España: Editorial Cátedra. Chevalier, J. (1986). Diccionario de los símbolos. Barcelona, España: Editorial Herder. 
Chilvers, I. (1995). Diccionario de arte. Madrid, España: Alianza Editorial.

Chinchilla-Ugalde, D. (2009). El adelantado Felo García. Nación Áncora. Recuperado de http://www.nacion.com/ancora/2009/enero/25/ancora1846154.html

De Micheli, M. (1993). Las vanguardias artísticas del siglo XX. Madrid, España: Alianza Editorial.

De la Nuez, J. (2014). Modernidad última en América Latina y posturas de la crítica artística. Aisthesis, 55, 197-212.

Deneb, L. (2001). Diccionario de símbolos: selección temática de los símbolos más universales. Madrid, España: Editorial Biblioteca Nueva.

Días-Bringas, T. (2003). En el trazo de las constelaciones. San José, Costa Rica: Ediciones Perro Azul.

Eco, U. (1997). Interpretación y sobreinterpretación. Cambridge, Inglaterra: Cambridge University Press.

Fernández-Chiti, J. (2003). Diccionario de estética de las artes plásticas. Buenos Aires, Argentina: Ediciones Condorhuasi.

González-Kreysa, A. (2007). Historia general del arte. San José, Costa Rica: EUNED.

Guardia, M. E. (2008). Treinta años atrás: la plástica nacional se introduce en las corrientes de vanguardia. Escena. Revista de las artes, 31(63), 45-52.

Lucie-Smith, E. (1983). El arte hoy: del expresionismo abstracto al nuevo realismo. Madrid, España: Cátedra.

Merizalde-Salazar, C. (2013). Reflexiones éticas y estéticas a partir de "Agonía permanente" (Tesis de Licenciatura en Artes). Universidad Central del Ecuador. Molina-Jiménez, I. (2005). Costa Rica del siglo XX al XXI. Historia de una sociedad. San José, Costa Rica: Editorial de la Universidad de Costa Rica. 
Molina-Jiménez, I. (2007). Identidad nacional y cambio cultural en Costa Rica durante la segunda mitad del siglo XX. San José, Costa Rica: Editorial de la Universidad de Costa Rica.

Pérez, Y. (2009). Manifiestos subyacentes de la obra artística de Felo García. Escena. Revista de las artes, 32(64), 71-79.

Real Academia Española. (2001). Diccionario de la Real Academia Española (22 ed., Vol. 2, tomos 2, 4, 5, 6, 7, 9 y 10). Colombia: ESPASA.

Ruhrberg, y Honnef, K. (2005). Arte del siglo XX. Köln, Alemania: Taschen.

Talens, J., Romera-Castillo, J., Tordera, A. y Vicente-Hernández, E. (1999). Elementos para una semiótica del texto artístico. Madrid, España: Cátedra.

Traba, Marta. (1994). Arte de América Latina 1900-1980. Banco Interamericano de Desarrollo.

Tresidder, J. (2003). Diccionario de los símbolos: una guía ilustrada para imágenes, íconos y emblemas tradicionales. México: Grupo Editorial Tomo.

Triana-Cambronero, M. A. (2013). Las tramas de Felo García. La Nación Áncora. Recuperado de http://wfnode01.nacion.com/2010-1031/Ancora/NotasSecundarias/Ancora2537543.aspx

Vargas-Durán, J. (1999). La producción cultural y la comunicación plástica en la modernidad. Revista Latina de Comunicación Social, 16. Recuperado de http://www.ull.es/publicaciones/latina/a1999iab/110vargas.htm

Zavaleta-Ochoa, E. (1994). Los inicios del arte abstracto en Costa Rica 1958-1971. San José, Costa Rica: Museo de Arte Costarricense. 